\title{
¿Son los indultos en España proporcionales a la pena impuesta?*
}

\section{Are pardons in Spain proportionals to sanctions?}

\author{
José Abreu \\ Juan Luis Jiménez \\ Universidad de Las Palmas de Gran Canaria
}

\begin{abstract}
Resumen
La figura del indulto, a pesar de su legalidad, genera controversia desde la perspectiva jurídica y social. En este trabajo, y utilizando una muestra de los indultos concedidos en España entre diciembre de 1995 y enero de 2013, perseguimos ahondar en el análisis de este tópico a través del estudio de la proporcionalidad de los indultos, entendida como la relación entre la pena indultada y/o conmutada y el tamaño de la pena originalmente impuesta. Los resultados señalan que se indulta más porcentaje a quienes más pena fue impuesta. Esta falta de proporcionalidad de los indultos se ve incrementada porque sea un gobierno conservador el que conceda el indulto; que se realice en época de bonanza económica; o que el indulto haya sido solicitado por una Cofradía, entre otros. El análisis confiere un mayor grado de subjetividad a esta controvertida figura.
\end{abstract}

Palabras clave: indultos, econometría, proporcionalidad, España.

Clasificación JEL.: K14, P48, Z18.

\begin{abstract}
The figure of pardon, despite its legality, generates controversy in the academic literature and among lawyers. In this paper, using a sample of pardons granted in Spain between December 1995 and January 2013, we seek to deepen the analysis of this topic through the study of their proportionality, understood as the relationship between the punishment pardoned and/or commuted and the size of the originally imposed sentence. Econometric results point out that pardons are not proportional: the greater the penalty imposed, the larger proportion that is pardoned. This lack of proportionality increases when the clemency is granted by a Conservative government; it is carried out in times of economic prosperity; or when the pardon has been requested by a Brotherhood (Cofradia), among others. These results confer a greater degree of subjectivity to this figure.

Keywords: pardons, econometrics, proportionality, Spain.
\end{abstract}

JEL classification: K14, P48, Z18.

* Los autores agradecen a la Fundación CIVIO y a Eva Belmonte por facilitarnos de forma altruista la base de datos original sobre los indultos concedidos en España, así como los comentarios recibidos de Eva Carracedo. Cualquier error es de nuestra entera responsabilidad.

DOI: https://doi.org/10.32796/cice.2019.97.6803 


\section{Introducción}

La figura del indulto está rodeada de controversias académicas y judiciales. Las primeras han mostrado los efectos negativos (Kwon et al., 2012) y la utilización sesgada de los mismos por parte de los Gobiernos que los conceden (Jiménez y Abreu, 2016); en tanto que las segundas la consideran como una intromisión del poder político en el judicial (Pérez y Domínguez, 2002; Sánchez-Vera, 2008; Santana, 2016).

Así, aunque el indulto -que supone la remisión total o parcial de una pena o sanción impuesta por una autoridad judicial, por parte del Gobierno- sea una medida que persista en la mayoría de países del mundo y cuyo principal argumento para su existencia está en que permite a quienes lo conceden corregir errores del sistema judicial (véase, por ejemplo, Heise, 2003), su concepto y ejecución no gozan de la transparencia y objetividad en los que debería basarse un instrumento que afecta al sistema judicial.

La literatura académica sobre esta materia se ha centrado en tres cuestiones principales. La primera hace referencia a los estudios de corte teórico-jurídicos, como podemos encontrar en Williston (1915), Fraile (2005), Eksterowicz y Roberts (2006), Barkow (2009) y Santana (2016), entre otros. La segunda línea se centra en el estudio desde una perspectiva de estadística descriptiva de los indultos, donde destacamos los trabajos de Doval et al. (2012), Herrero (2012) o Madrid (2014). En tanto que la tercera vía de investigación está enfocada al análisis de las relaciones de determinación de la concesión de indultos y los factores que pudieran incidir sobre estos, como los trabajos de Ruckman $(1997,1998)$, Morris (1998), Austin y Hummer (2000), Whitford y Ochs (2006) y Harmon et al. (2010).

El trabajo más reciente, y que comparte la base de datos del presente estudio, es el de Jiménez y Abreu (2016), donde los autores analizan qué factores afectan en España al número de indultos concedidos y a la celeridad en dicha concesión. Sus estimaciones econométricas confirman que existe cierto sesgo en la concesión de los indultos -se conceden menos indultos en periodos cercanos a las elecciones-, así como una mayor celeridad en los mismos para aquellos casos en los que la multa es mayor o cuando se trata de una persona que ha ejercido un cargo público, como Alcalde o Concejal.

A este respecto, Santana (2016), desde un punto de vista teórico-jurídico, señala que los indultos por delitos de corrupción deterioran la confianza en el sistema penal, y que sus efectos sobre el mismo son difícilmente cuantificables, más si se siguen concediendo indultos masivos en un contexto de aumento de condenados por delitos de corrupción.

Por su parte, Badules (2016) también lleva a cabo un análisis cuantitativo -y cualitativo- de los indultos en España, encontrando una correlación positiva entre la cuantía de los presupuestos, el número de empleados públicos, el número de condenas, el tamaño de la población reclusa y el número de indultos otorgados, mientras que observa una relación negativa entre el número de solicitudes y la atención del Congreso en la concesión de indultos. 
Pero más allá de la propia concesión del indulto se encuentra una segunda fase, que es determinar qué porcentaje de la pena indulta o conmuta el Gobierno al individuo. En este punto, y hasta donde conocemos, no existe literatura al respecto que evalúe cuantitativamente si existe alguna relación entre dicho porcentaje y la pena impuesta lo que, haciendo un paralelismo con la clasificación de los impuestos según su tipo impositivo, estaríamos hablando de proporcionalidad (o no) en los indultos. Así, en este caso, perseguimos evaluar cómo es el porcentaje de pena indultada o conmutada por parte del gobierno cuanto mayor sea la sanción impuesta por el tribunal sentenciador: mayor, proporcional o menor.

Es por ello que el objetivo del presente trabajo es el de cuantificar econométricamente la relación entre ambos hechos (porcentaje indultado y/o conmutado $v s$ pena impuesta), pero controlando simultáneamente otros factores que puedan estar afectando a dicho porcentaje.

Tras esta introducción, la sección segunda explica la base de datos conformada y sus principales estadísticos descriptivos para, en la sección tercera detallar la estrategia empírica y los principales resultados de esta. Dichos resultados apuntan en la misma línea de los trabajos anteriores, pero desde otra perspectiva: en España, los Gobiernos conceden mayores porcentajes de indulto o conmuta de pena a aquellos reos con sanciones privativas de libertad mayores.

\section{Base de datos}

Para conocer cuáles son aquellos factores que pueden influir en el porcentaje de pena indultada, disponemos de una base de datos, originalmente proporcionada por la Fundación Ciudadana $\mathrm{CIVIO}^{1}$, que recopila información acerca de los 10.205 indultos concedidos en España entre diciembre de 1995 y enero de 2013.

No obstante, la muestra empleada en este estudio asciende a 4.754 indultos (un 47 por 100 del total de indultos) $)^{2}$, ya que se trata de aquellos individuos cuyo indulto (total o parcial) o conmuta se hace con respecto a la pena privativa de libertad, privativa de derecho o multa impuesta, de manera que el cálculo del porcentaje de pena indultada es factible, puesto que la referencia es la pena impuesta en la sentencia firme. Por el contrario, los condenados cuyo indulto o conmuta recaiga sobre las penas privativas (de libertad o derecho) o multa pendiente de cumplimiento, no han sido incluidos en la muestra. Esto es debido a que, como se desconoce la fecha de ingreso en prisión o cuándo empezó a cumplir la condena, no es posible calcular el

\footnotetext{
1 www.civio.es.

${ }^{2}$ No se ha tenido en cuenta aquellos en cuyas sentencias no se recogía una pena privativa de libertad (solo pena privativa de derecho o multa) o cuyo indulto o conmuta no recaía sobre la pena privativa de libertad. También hay reos para los que no se tenía información del tipo de pena privativa de derecho aplicada, pues en el Real Decreto solo rezaba «con las accesorias legales». Además, no han sido empleados en este estudio los condenados por órganos judiciales extranjeros y aquellos cuya pena era conmutada por trabajos comunitarios por considerarlos poco representativos.
} 
porcentaje de pena indultada, porque no se tiene conocimiento de cuánto le restaba por cumplir al individuo.

En el Gráfico 1 se muestra la evolución temporal, tanto de los indultos totales concedidos en el período como de los indultos que finalmente componen la muestra considerada. Como se puede apreciar, las series tienen un comportamiento tendencial muy similar, con un coeficiente de correlación del 83 por 100 y el 86 por 100 para la muestra de 4.754 y la de $4.512^{3}$ observaciones respectivamente. Por tanto, la muestra es representativa, tanto por los elevados porcentajes de muestreo como por dicho componente tendencial (véase Cuadro A.I, que recoge la representatividad de la muestra por años).

Es necesario destacar el elevado número de indultos en los años 1998 y 2000. Mientras que en 1998 la mayoría de indultados habían sido condenados por delitos de insumisión y se les concedió la gracia tras la aprobación de una Ley que suprimía la obligatoriedad del cumplimiento del servicio militar, en el 2000 se indultaron numerosos condenados a petición del Papa Juan Pablo II por tratarse de un Año Jubilar y por la entrada en el nuevo milenio.

Como comentamos en la introducción, uno de los principales valores añadidos del trabajo es que para la obtención de cada una de las variables, se procedió a la lectura de cada uno de los 10.205 Reales Decretos de indultos publicados en el Boletín Oficial del Estado en el período de estudio, a partir de los cuáles se conformaron la mayoría de estas variables.

A continuación, se detallan las variables empleadas en el análisis, siendo la primera la variable dependiente del modelo empírico que será objeto de estudio en la sección siguiente:

1. Porcentaje de pena indultada $a_{i t}$ porcentaje de las penas privativas de libertad impuestas al individuo $i$ que han sido indultadas (total o parcialmente) o conmutadas por otras menos graves en el año $t$ (1995-2013). Es calculada como el número de días de pena indultados entre el número de días de penas privativas de libertad impuestas. Como se adelantó, no se han considerado aquellos individuos cuyos indultos recayeron sobre las penas pendientes de cumplimiento. (Fuente: Elaboración propia).

2. Días de pena privativa de libertad: es la suma de los días de penas privativas de libertad a los que ha sido condenado el individuo $i$. Es lógico pensar que el número de días de condena de un individuo va acorde a la gravedad del delito, de manera que cuanto más significativo es el delito, mayor es la pena, y menor será el porcentaje de pena indultada. (Fuente: Elaboración propia).

${ }^{3}$ Tal y como se señala más adelante, en una de las estimaciones las observaciones disminuyen hasta 4.512 individuos como consecuencia de la variable «días transcurridos», ya que en la muestra hay militares para los cuales no se disponía de la fecha de sentencia, de manera que su cálculo no era factible por la ausencia de esa fecha referencia. Debido a esto, no se incluye la estimación del coeficiente de la variable «indulto total», ya que este tipo de indultos solo fue concedido a militares. 


\section{GRÁFICO 1}

\section{INDULTOS TOTALES Y MUESTRALES}

(diciembre 1995-enero 2013)

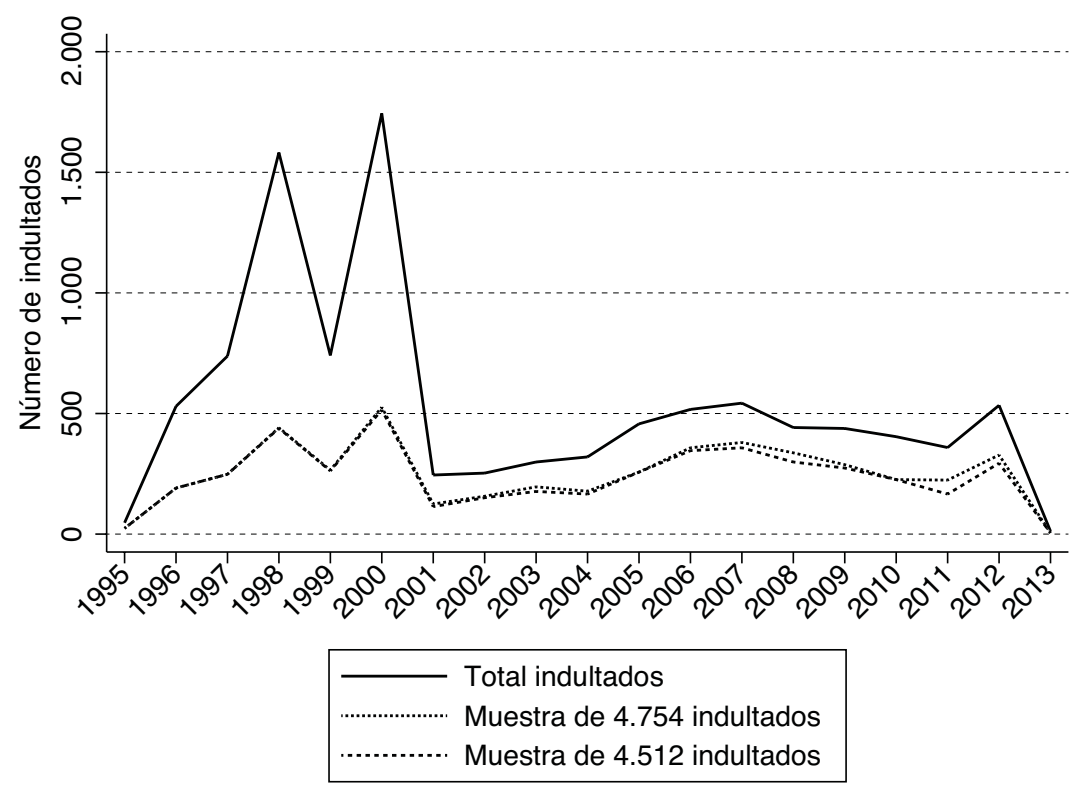

FUENTE: Elaboración propia a través de Civio.

NOTA: Los años 1995 y 2013 solo incluyen los meses de diciembre y enero, respectivamente.

3. Multa: cuantía de la multa impuesta (en euros) al individuo $i$ por los delitos que este cometiese. Se espera que tenga un efecto negativo sobre el porcentaje de pena indultada, pues la multa es un indicador de la gravedad del delito. (Fuente: Elaboración propia a partir de Civio).

4. Género: ${ }_{i}$ variable binaria que toma valor 1 si el indultado $i$ es un hombre y 0 en caso contrario. Tal y como señalan Doval et al. (2012), se concederán más indultos a mujeres que a hombres, debido a factores como la menor peligrosidad o las responsabilidades familiares. Por tanto, la hipótesis de partida es que los hombres recibirán un porcentaje de indulto de pena menor que las mujeres. (Fuente: Elaboración propia a partir de Civio).

5. Número de delitos: ${ }_{i}$ número de delitos cometidos por el individuo $i$. El efecto esperado de esta variable sobre la dependiente es parecido al de la variable multa. (Fuente: Elaboración propia a partir de Civio).

6. Ideología: variable binaria que toma valor 1 si el indulto es concedido, en el año $t$ (1995-2013), por un ministro de Justicia o de Defensa del Partido Popular (en adelante, PP) y 0 en caso de que se trate de un ministro del Partido Socialista Obrero Español (en adelante, PSOE). Algunos autores (Ruckman, 1997; Borja, 2011) consideran que los partidos progresistas son más indulgentes que los conservadores, de manera que se espera que 
el PSOE sea propenso a indultar una mayor pena. No obstante, Jiménez y Abreu (2016) encuentran que el PP indulta más rápido que el PSOE. (Fuente: Elaboración propia).

7. Insumiso: variable binaria que toma valor 1 si el individuo indultado $i$ es un insumiso y 0 en caso contrario. Un «insumiso» es aquel condenado que ha cometido un delito de negativa a la prestación del servicio militar o la prestación social sustitutoria, y cuya obligatoriedad fue abolida el 31 de diciembre de $2001^{4}$. Están incluidos en las estimaciones como variable de control tanto porque representan cerca del 10 de la muestra (464 insumisos) como por haber sido indultados muchos de ellos de forma conjunta. (Fuente: Elaboración propia).

8. Días transcurridos: días que transcurren desde que el individuo $i$ es condenado por sentencia firme hasta que es indultado ${ }^{5}$. Se espera que el indulto sea mayor cuanto mayor sea el tiempo transcurrido, pues puede considerarse que el individuo ha cumplido su condena y ya está rehabilitado, aunque también puede ser por motivos de salud o edad, aspectos que refuerzan los argumentos para conceder un indulto. (Fuente: Elaboración propia).

9. Nueva multa: variable binaria que toma valor 1 si en la nueva sentencia del individuo $i$, el indulto o la conmuta de la pena impuesta se lleva a cabo mediante su sustitución por una multa, o dicha multa sirve como complemento a la conmutación de la pena por otra menos grave, y 0 en caso contrario. Consideramos que un individuo cuya pena sea indultada o conmutada por una nueva multa recibirá un perdón mayor, ya que el suprimido artículo 88 del Código Penal señalaba que las penas de prisión que no excedieran de un año podrían ser sustituidas por una multa o trabajos en beneficio de la comunidad. (Fuente: Elaboración propia).

10. Legislaturas: ${ }_{i}$ variable binaria que toma valor 1 para cada una de las seis legislaturas que ha habido durante el período de estudio $t(1995-2013)^{6}$. La legislatura de referencia es la de 2004-2008, puesto que en la muestra recogida es donde más indultos se concedieron (1.192 indultos). Jiménez y Abreu

\footnotetext{
${ }^{4}$ Real Decreto 247/2001, 9 de marzo, por el que se adelanta la suspensión de la prestación del servicio militar. En la base de datos final han sido incluidos 130 insumisos que, se conoce, no estuvieron en prisión y cuyo indulto recaía sobre las penas privativas de libertad pendientes de cumplimiento. Este dato puede comprobarse mediante la transcripción de las ruedas de prensa dadas por Miguel Ángel Rodríguez Bajón, Secretario de Estado de Comunicación del PP entre 1996 y 1998, con fechas del 06/03/1998 (14 insumisos), 13/03/1998 (22), 20/03/1998 (27), 02/04/1998 (38), 19/06/1998 (20) y 10/07/1998 (9). En este último Consejo de Ministros se concedieron en total 20 indultos a insumisos, 11 de los cuales estaban en prisión y cuyos expedientes de indulto fueron tramitados por «Orden de la Ministra de Justicia», en aquel entonces, Margarita Mariscal de Gante y Mirón. Véase, por ejemplo, el Real Decreto 1520/1998, de 10 de julio, por el que se concede dicho indulto.

${ }^{5}$ La inclusión de esta variable en el modelo viene dada porque, en palabras de Miguel Ángel Rodríguez Bajón, en la rueda de prensa del jueves 31 de octubre de 1996, después de una reunión del Consejo de Ministros, «un factor que se ha tenido en cuenta, a la hora de valorar la concesión de los indultos, es que hubiera transcurrido un largo período de tiempo desde la fecha de la comisión de los hechos hasta el momento en que se ha concedido el indulto...».

${ }^{6}$ Son, a saber: las legislaturas de 1993-(diciembre 1995)-1996 (PSOE), 1996-2000 (PP), 2000-2004 (PP), 2004-2008 (PSOE), 2008-2011 (PSOE) y 2011 (enero 2013) 2015 (PP).
} 
(2016) señalan que la concesión de indultos se ve afectada por la legislatura, y aquí esperamos que en las legislaturas previas a la crisis económica los porcentajes de indulto sean mayores, pues una coyuntura de crisis económica y social desincentiva a los políticos a la hora de conceder indultos. Muestra de ello es el Gráfico 2, donde puede verse cómo el número de indultos ha disminuido significativamente desde $1996^{7}$. (Fuente: Elaboración propia).

11. Tipo de delito: variables binarias que toman valor 1 en función del tipo de delito principal cometido por el indultado $i$, atendiendo a la clasificación establecida en el Código Penal, Libro II (Delitos y sus penas), Títulos I-XXIV. En total han sido 21 tipos $^{8}$, siendo la categoría de referencia el Título XVII (De los delitos contra la seguridad colectiva), cuyo número asciende a 1.840 indultos concedidos, y que engloba especialmente delitos contra la salud pública. Estas variables son empleadas como una variable de control, por si dependiendo del tipo existiesen patrones de indulto y/o conmuta común. (Fuente: Elaboración propia).

12. Grado de participación $n_{i}$ variables binarias que controlan el grado de responsabilidad del individuo $i$ en la comisión del delito, y que son tres: autor/a, cooperador necesario o cómplice. Se espera que los cómplices y cooperadores necesarios tengan una reducción de la pena mayor, en comparación con el autor principal del delito. (Fuente: Elaboración propia).

13. Tipo de indulto: $:$ variables binarias que enumeran la clase de indulto que se le concede al individuo $i$ atendiendo a la clasificación realizada por la propia Ley: indulto total, parcial o conmuta ${ }^{9}$. La conmuta es el tipo de indulto de referencia (4.016 conmutaciones). Se espera que los individuos a los que conceden el indulto total tengan una reducción de la pena mayor, mientras que el efecto sobre aquellos a los que se le aplica el indulto parcial no es claro. (Fuente: Elaboración propia).

14. Incoado por: variables binarias que recogen las vías por las que ha sido solicitado el expediente de indulto, teniendo en cuenta la clasificación hecha por Madrid $(2014)^{10}$, y que son: particular ${ }^{11}$, juez o tribunal sentenciador

${ }^{7}$ http://www.elindultometro.es/2016/02/17/actualizacion-2015.html

${ }^{8}$ Hay títulos del Libro II del Código Penal para los cuales no hay observaciones en la muestra. Para los delitos cometidos por el colectivo militar, se ha tenido en cuenta la clasificación hecha por CIVIO en «El indultómetro», que los engloba dentro del «Código Penal Militar».

${ }^{9}$ Según el artículo 4 de la Ley de 18 de junio de 1870, reformada por la Ley 1/1988 de 14 de enero, el indulto total recaerá sobre todas las penas que el condenado aún no hubiera cumplido (en la base de datos original solo se ha concedido este tipo de indulto a militares). El indulto parcial supone la remisión de las penas impuestas o pendientes de cumplimiento y la conmuta implica la sustitución de la pena por otra menos grave.

${ }^{10}$ Aunque Madrid (2014) considera que los expedientes de indulto de condenados por Tribunales Militares son «a propuesta del Ministro de Defensa», en este estudio se ha optado por obviar dicha clasificación, de manera que se trataron como indultos solicitados por particulares. No existen evidencias de que se hayan concedido indultos en virtud del artículo 41 del Código Penal Militar.

${ }^{11} \mathrm{Si}$ en el Real Decreto no se hace referencia a otras vías para solicitar el indulto, se ha considerado que el expediente de indulto ha sido solicitado por el penado, sus parientes o cualquier otra persona en su nombre (artículo 19 de la Ley de 1870). 
(artículo 4.3 del Código Penal), equipo técnico del centro penitenciario (artículo 206.1 del Código Penitenciario) y cofradías ${ }^{12}$. Los indultos solicitados por los particulares son la variable de referencia (4.120 indultos). (Fuente: Elaboración propia a partir del Boletín Oficial del Estado, BOE).

15. Tipo de pena privativa de derecho ${ }_{i}$ : variables binarias que resumen el tipo de pena privativa de derecho o accesoria (inhabilitación especial, inhabilitación absoluta, suspensión de empleo o cargo público, etc., hasta ocho tipos) impuesta al individuo $i$. La pena de referencia es la de inhabilitación especial (2.471 indultos), que engloba la inhabilitación para empleo o cargo público, profesión, oficio, derecho de sufragio pasivo y patria potestad, entre otros. Son utilizadas como variables de control. (Fuente: Elaboración propia).

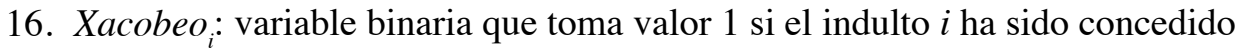
en diciembre del año 2000, a fin de controlar las medidas de gracia aprobadas con motivo del Año Jubilar y el fin del milenio ${ }^{13}$. Se espera que su efecto sobre la pena indultada sea ambiguo. (Fuente: Elaboración propia).

\section{GRÁFICO 2 \\ INDULTOS POR AÑO (1996-2015)}

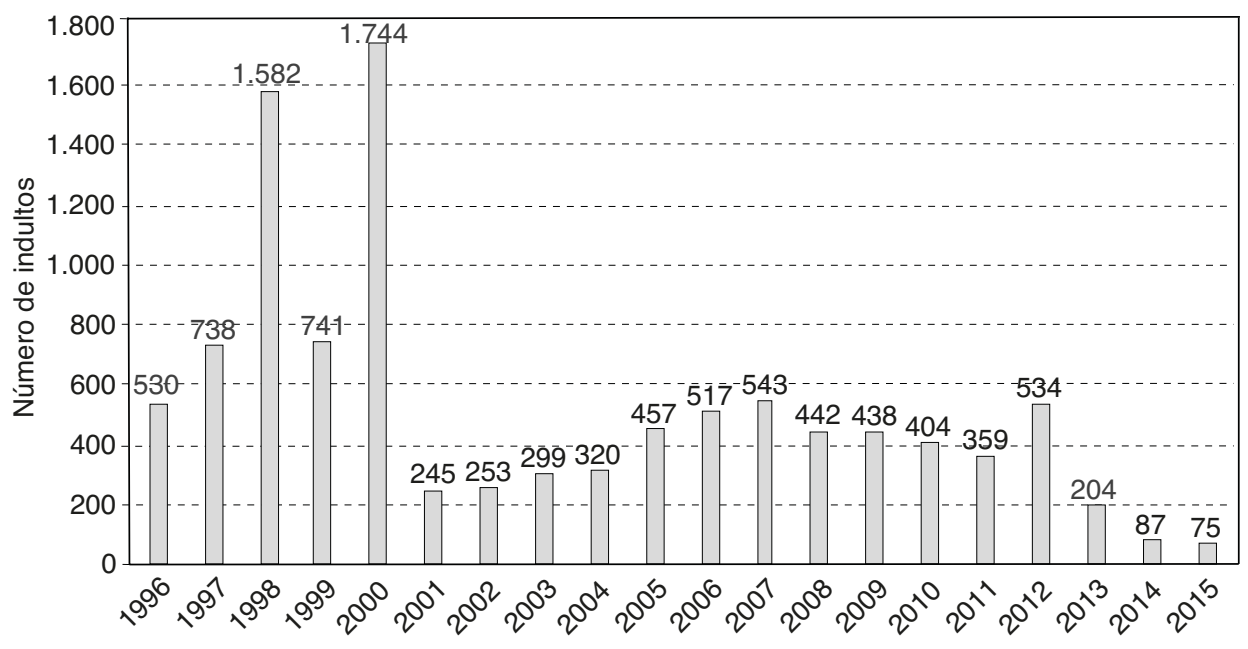

FUENTE: Elaboración propia a partir de los datos de la Fundación CIVIO.

\footnotetext{
${ }^{12}$ Véase, por ejemplo, las Referencias del Consejo de Ministros del 23/03/2012 y el 30/03/2012, por el que se concedieron un total de 19 indultos especiales con motivo de la Semana Santa.

${ }^{13}$ Comparecencia del Ministro de Justicia en la sesión del 13/12/2000 de la Comisión de Justicia e Interior (citado en Doval et al., 2012).
} 
El Cuadro 1 resume los estadísticos descriptivos empleados en este estudio. Como se puede observar, el porcentaje medio de pena privativa de libertad indultada o conmutada es del 50 por 100, mientras que el número de días de condena media es de 1.243 (aproximadamente tres años y cinco meses de pena). La multa media es de 214.859 euros, aunque esta muestra una gran variabilidad. Los hombres representan el 83 por 100 de los indultados de la muestra y el número de delitos medios que se cometen es de 1,27. Por último, el 51 por 100 de los indultos de la muestra han sido concedidos por el PP, en tanto que el número medio de días transcurridos entre sentencia e indulto es de 1.111 (alrededor de tres años y un mes).

Por su parte, la variable endógena muestra amplia variabilidad y, para mostrar gráficamente ese recorrido, realizamos el análisis box-plot en el Gráfico $3^{14}$.

\section{CUADRO 1 \\ ESTADÍSTICOS DESCRIPTIVOS \\ (diciembre 1995-enero 2013)}

\begin{tabular}{|l|c|c|c|c|c|}
\hline \multicolumn{1}{|c|}{ Variables } & $\begin{array}{c}\text { Observa- } \\
\text { ciones }\end{array}$ & Media & $\begin{array}{c}\text { Desviación } \\
\text { estándar }\end{array}$ & Mínimo & Máximo \\
\hline Porcentaje de pena indultada & 4.754 & 0,50 & 0,26 & 0,001 & 1 \\
\hline Días de pena privativa de libertad & 4.754 & $1.243,01$ & $1.301,33$ & $29^{\mathrm{a}}$ & $60.395^{\mathrm{b}}$ \\
\hline Multa (euros) & 4.832 & $214.859,3$ & 5.126 .856 & 0 & $2.44 \mathrm{e}^{\mathrm{c}} 8^{\mathrm{c}}$ \\
\hline Género & 4.832 & 0,83 & $(-)$ & 0 & 1 \\
\hline Número de delitos & 4.832 & 1,27 & 2,08 & 1 & $98^{\mathrm{d}}$ \\
\hline Ideología & 4.832 & 0,51 & $(-)$ & 0 & 1 \\
\hline Insumiso & 4.832 & 0,10 & $(-)$ & 0 & 1 \\
\hline Días transcurridos & 4.589 & $1.111,25$ & 748,61 & $114^{\mathrm{e}}$ & $8.261^{\mathrm{f}}$ \\
\hline Nueva multa & 4.832 & 0,02 & $(-)$ & 0 & 1 \\
\hline
\end{tabular}

${ }^{\text {a }}$ Real Decreto 2673/1996, de 27 de diciembre, por el que se concede dicho indulto (BOE-A-1997-1275).

${ }^{\mathrm{b}}$ Real Decreto 2390/2000, de 1 de diciembre, por el que se concede dicho indulto (BOE-A-2000-23426).

${ }^{c}$ Real Decreto 516/2012, de 9 de marzo, y Real Decreto 1212/2012, de 3 de agosto, por los que se conceden ambos indultos (BOE-A-2012-4215 y BOE-A-2012-11184, respectivamente).

${ }^{\text {d }}$ Real Decreto 1477/2009 y Real Decreto 1480/2009, de 18 de septiembre, por los que se conceden ambos indultos (BOE-A-2009-15983 y BOE-A-2009-15986, respectivamente).

${ }^{\text {e }}$ Real Decreto 1027/2003, de 25 de julio, por el que se concede dicho indulto (BOE-A-2003-15932).

${ }^{\mathrm{f}}$ Real Decreto 2730/2000, de 1 de diciembre, por el que se concede dicho indulto (BOE-A-2000-24050). Aunque el indulto se aplica sobre la pena privativa de libertad pendiente de cumplimiento, en el Real Decreto se especifica que al individuo le restan 36 días por cumplir, por lo que el cálculo del porcentaje de pena indultada es posible.

FUENTE: Elaboración propia y CIVIO.

${ }^{14}$ Recordemos que las cajas recogen los valores que se encuentran entre los puntos del percentil 25 y el percentil 75 . 


\section{GRÁFICO 3}

BOX-PLOT DE PORCENTAJE PENA INDULTADA, SEGÚN GOBIERNOS

(diciembre 1995-enero 2013)

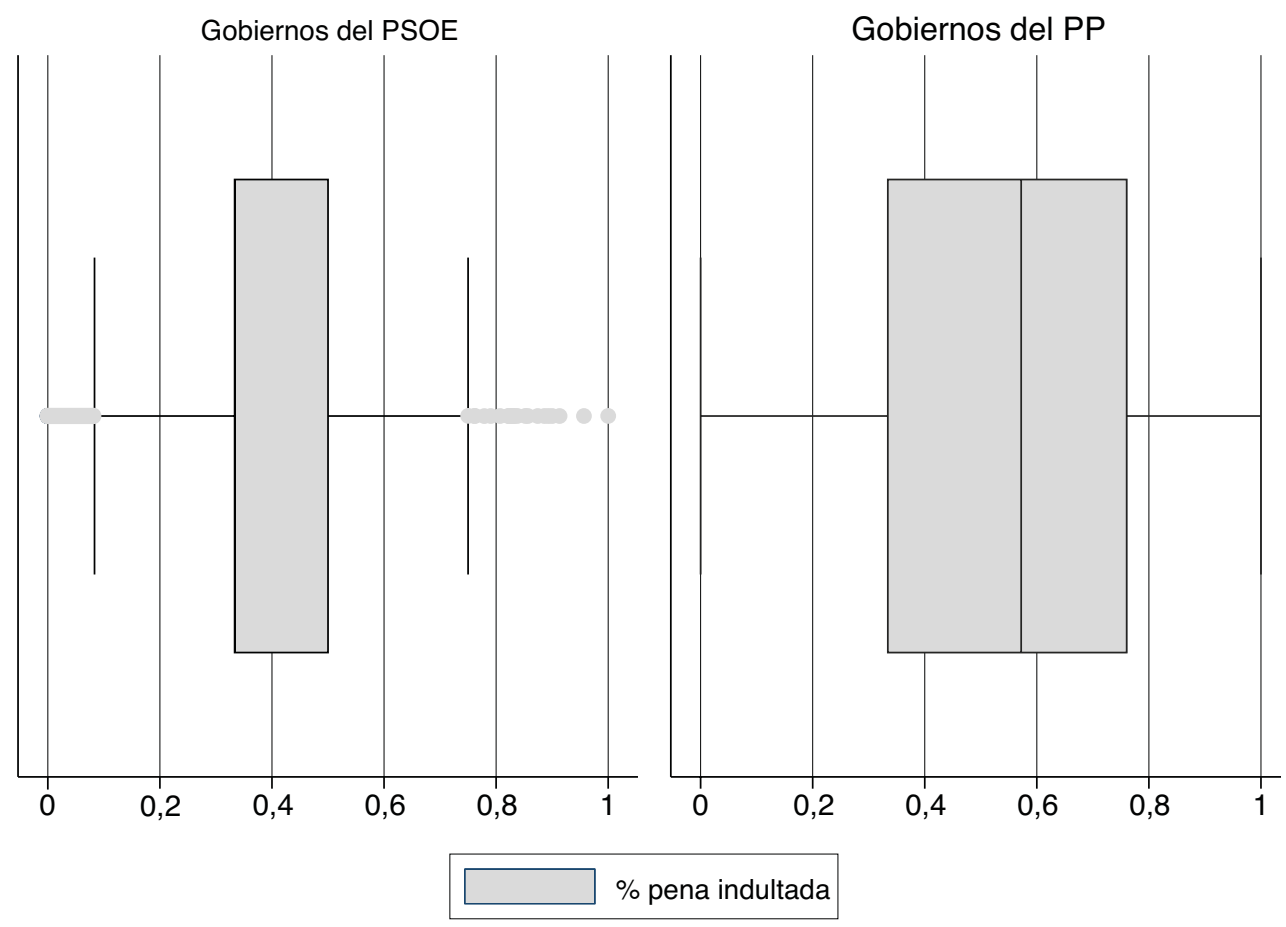

FUENTE: Elaboración propia.

En este análisis gráfico se observa cómo los gobiernos del Partido Popular han concedido porcentajes de conmuta de penas más altos. De hecho, los valores medios para el PP son del 58 por 100, en tanto que para el Partido Socialista son del 39 por 100. No obstante, pueden existir otra serie de factores que incidan en tales porcentajes, que pretendemos confirmar con las estimaciones de la sección siguiente.

\section{Estrategia empírica y resultados}

Nuestro objetivo es determinar la relación (si existe) entre el porcentaje de pena indultada y la pena originalmente impuesta, pero considerando simultáneamente el resto de factores que puedan afectar a dicha variable a explicar. En realidad lo que estamos obteniendo son porcentajes medios condicionados a los factores explicativos de tal resultado. 
De esta forma, la ecuación que estimamos es la siguiente (ecuación [1]), por el método de mínimos cuadrados ordinarios, que, dada la estructura de los datos, es el más factible:

$$
\begin{aligned}
& \%_{\text {Penaindultada }}=\beta_{0}+\beta_{1} \text { Diaspena }_{i}+\beta_{2}\left(\text { Diaspena }_{i}^{2}+\beta_{3} \text { Multa }_{i}+\beta_{4} \text { Género }_{i}+\beta_{5} \text { Númerodelitos }_{i}+\right. \\
& +\beta_{6} \text { Ideología }_{t}+\beta_{7} \text { Insumiso }_{i}+\sum_{j=8}^{12} \beta_{j} \text { Legislatura }_{t}+\beta_{13} \text { Cómplice }_{i}+\beta_{14} \text { Cooperador }_{i}+\beta_{15} \text { Indultoparcial }_{i}+ \\
& +\beta_{16} \text { Indultototal }_{i}+\beta_{17} \text { Cofradía }_{i}+\beta_{18} \text { Equipotécnico }_{i}+\beta_{19} \text { Tribunalsentenciador }_{i}+\beta_{20} \text { Nuevamulta }_{i}+ \\
& +\beta_{21} \text { Diastranscurridos }_{i}+\sum_{j=22}^{41} \beta_{j} \text { Tipodelito }_{i}+\sum_{j=42}^{48} \beta_{j} \text { Tipopenaprivativa }_{i}+\varepsilon_{i t}
\end{aligned}
$$

La estrategia empírica que hemos ejecutado es la de incluir progresivamente en las estimaciones 1 a la 3, otras variables que puedan afectar también a la relación principal. Con ello se pretende comprobar la robustez de las variables, esto es, si su signo y significatividad varían o no de una estimación a otra.

Así, la ecuación 1 incluye como explicativas la base del modelo, a saber: los días de pena privativa de libertad (y su cuadrado), la multa impuesta (en euros), el género del indultado, el número de delitos que cometió, si este era insumiso, el Año Jubilar, qué gobierno le indultó, el grado de implicación, el tipo de indulto, quién solicitó el indulto, si la pena es sustituida o complementada por una multa, así como el tipo de delito y de pena privativa. Posteriormente incluimos las legislaturas (estimación 2) y finalmente los días transcurridos entre la sentencia y la concesión del indulto $(\text { estimación } 3)^{15}$.

Los resultados de estas estimaciones se encuentran en el Cuadro 2.

Las estimaciones muestran una bondad del ajuste superior al 65 por 100 en todos los casos, manteniendo todas las variables su significatividad y signo tras la introducción de nuevos regresores en las estimaciones 1 a la 3, lo que da muestras de su robustez dentro del modelo.

Así, la principal relación que queríamos contrastar muestra cómo aquellos individuos con mayores días de pena privativa de libertad obtienen un porcentaje de indulto o conmutación de pena mayor. Este resultado nos llevaría a considerar los indultos en España como no proporcionales desde un punto de vista judicial. No obstante, el signo negativo de la variable al cuadrado nos muestra un crecimiento cuadrático de ese cambio con respecto al tamaño de los días de pena privativa, lo que indica que a medida que los delitos son más graves, menor es el porcentaje de indulto o conmuta concedido.

${ }^{15}$ Como ya se comentó con anterioridad, en la estimación 3, las observaciones disminuyen hasta 4.512 individuos como consecuencia de la variable «días transcurridos», ya que en la muestra hay militares para los cuales no se disponía de la fecha de sentencia, de manera que su cálculo no era factible por la ausencia de esa fecha referencia. Debido a esto, no sale el coeficiente de la variable «indulto total», ya que este tipo de indultos solo fue concedido a militares. 


\section{CUADRO 2}

PORCENTAJE DE PENA INDULTADA POR INDIVIDUO. MÍNIMOS CUADRADOS ORDINARIOS

\begin{tabular}{|c|c|c|c|}
\hline Variables explicativas & Estimación 1 & Estimación 2 & Estimación 3 \\
\hline Días de pena privativa de libertad & $1,4 \mathrm{e}-05(5 \mathrm{e}-06) * * *$ & $1,1 \mathrm{e}-05(5 \mathrm{e}-06)^{* *}$ & $1,1 \mathrm{e}-05(5 \mathrm{e}-06)^{*}$ \\
\hline$\left(\right.$ Días de pena privativa de libertad) ${ }^{2}$ & $-4 \mathrm{e}-10(9 \mathrm{e}-11) * * *$ & $-3,3 \mathrm{e}-10(9 \mathrm{e}-11) * * *$ & $-3,3 \mathrm{e}-10(8 \mathrm{e}-11) * * *$ \\
\hline Multa (euros) & $-4 \mathrm{e}-10(1,1 \mathrm{e}-10)^{* * *}$ & $-3,7 \mathrm{e}-10(9 \mathrm{e}-11) * * *$ & $-3,2 \mathrm{e}-10(9 \mathrm{e}-11) * * *$ \\
\hline Género & $-0,001(0,006)$ & $1,1 \mathrm{e}-04(0,006)$ & $-0,001(0,006)$ \\
\hline Número de delitos & $-0,002(0,001)^{* *}$ & $-0,002(0,001)^{* *}$ & $-0,002(7,5 \mathrm{e}-04) * * *$ \\
\hline Ideología & $0,04(0,004)^{* * *}$ & & \\
\hline Insumiso & $0,28(0,10)^{* * *}$ & $0,26(0,11)^{* *}$ & $0,26(0,11)^{* *}$ \\
\hline Legislatura 93(95)-96 & & $0,10(0,01)^{* * *}$ & $0,13(0,01)^{* * *}$ \\
\hline \begin{tabular}{|l|} 
Legislatura 96-00 \\
\end{tabular} & & $0,14(0,01)^{* * *}$ & $0,16(0,01)^{* * *}$ \\
\hline Legislatura 00-04 & & $0,03(0,008) * * *$ & $0,04(0,01)^{* * *}$ \\
\hline Legislatura 08-11 & & $0,004(0,007)$ & $-0,004(0,009)$ \\
\hline Legislatura 11-15(13) & & $0,01(0,02)$ & $0,01(0,02)$ \\
\hline Cómplice & $-0,007(0,03)$ & $-0,02(0,03)$ & $-0,007(0,03)$ \\
\hline Cooperador necesario & $0,11(0,05)^{* *}$ & $0,09(0,05)^{* *}$ & $0,10(0,05)^{* *}$ \\
\hline Indulto parcial & $-0,06(0,02)^{* * *}$ & $-0,05(0,01)^{* *}$ & $-0,07(0,01)^{* * *}$ \\
\hline Indulto total & $0,35(0,03)^{* * *}$ & $0,36(0,03) * * *$ & \\
\hline Cofradía & $0,09(0,04)^{* *}$ & $0,10(0,04)^{* *}$ & $0,10(0,04)^{* *}$ \\
\hline Equipo técnico & $-0,24(0,02)^{* * * *}$ & $-0,21(0,03)^{* * *}$ & $-0,20(0,02)^{* * *}$ \\
\hline Tribunal sentenciador & $0,04(0,009)^{* * *}$ & $0,02(0,009) * * *$ & $0,02(0,009)^{* *}$ \\
\hline Nueva multa & $0,34(0,07)^{* * *}$ & $0,34(0,06) * * *$ & $0,34(0,06)^{* * *}$ \\
\hline Xacobeo & $0,02(0,04)$ & $0,12(0,04)^{* * *}$ & $0,11(0,01)^{* *}$ \\
\hline Días transcurridos & & & $2 \mathrm{e}-05(5 \mathrm{e}-06) * * *$ \\
\hline Tipo de delito & Sí & Sí & Sí \\
\hline Tipo de pena privativa de derecho & Sí & Sí & Sí \\
\hline Constante & $0,33(0,009)^{* * *}$ & $0,33(0,01)^{* * *}$ & $0,32(0,01)^{* * *}$ \\
\hline $\begin{array}{l}\text { Observaciones } \\
R^{2}\end{array}$ & $\begin{array}{c}4.754 \\
0,65\end{array}$ & $\begin{array}{c}4.754 \\
0,66\end{array}$ & $\begin{array}{c}4.512 \\
0,66\end{array}$ \\
\hline
\end{tabular}

FUENTE: Elaboración propia.

NOTA $1: * * * 1$ por $100, * * 5$ por $100, * 10$ por 100 . Nivel de significatividad de la variable. Errores estándar robustos incluidos entre paréntesis.

NOTA 2: La significatividad conjunta de los modelos no es reportada por el software STATA como consecuencia del empleo de un cluster por provincia. 
Por tanto, los tribunales proponen mayores indultos cuanto mayor es la pena, quizá porque ese indulto ha sido concedido por motivos de buena conducta, familiares, edad o enfermedad ${ }^{16}$, aunque no son tan condescendientes en aquellos delitos muy graves.

Respecto de la multa, la relación es negativa. Para aquellos individuos cuya pena es principalmente monetaria, la pena indultada o conmutada es menor cuanto mayor sea la multa impuesta. De esta forma, tal y como se señaló anteriormente, la cuantía de la multa es un indicador de la gravedad del delito, de manera que los tribunales tienen en cuenta este hecho para decidir si conceden un indulto más o menos generoso. Con esta misma variable, Jiménez y Abreu (2016) mostraron que los individuos con una mayor multa conseguían el indulto más rápidamente.

En la misma línea se encuentra la variable de «número de delitos», donde cuanto mayor haya sido ese número, la reducción porcentual de la pena es menor. La interpretación es parecida a la de la variable multa, ya que si un individuo ha cometido un mayor número de delitos, más grave será la sentencia y, por ende, es un factor a tener en cuenta a la hora de decidir sobre el indulto.

Como apuntaban los datos descriptivos, aunque en menor medida, el coeficiente positivo y significativo de la variable «ideología» señala que los gobiernos del Partido Popular conceden en media una conmuta de pena superior a los del PSOE en cuatro puntos porcentuales. Por tanto, los resultados no permiten corroborar la hipótesis de partida de que los partidos progresistas son más indulgentes que los conservadores, hecho recogido también en el estudio de Jiménez y Abreu (2016). Esto puede deberse a que el PP llevó a cabo una serie de indultos excepcionales en 1998 y 2000, los primeros concedidos a insumisos condenados por negarse a prestar el servicio militar, y los segundos como respuesta a una petición del entonces Papa Juan Pablo II, la entrada del nuevo milenio, el 22 aniversario de la Constitución Española o la celebración del año Jubilar ${ }^{17}$.

En cuanto a los efectos temporales, se observa cómo en época reciente, y de crisis económica, no hay porcentajes de conmuta significativamente diferentes de los concedidos en el período 2004-08, que es el de referencia. No obstante, todas las legislaturas anteriores sí señalan descuentos mayores que esta. Esto puede deberse a la creciente preocupación que se ha ido instaurando en la sociedad española, en lo que se refiere al uso de esta figura, como consecuencia del contexto socio-económico que atraviesa el país, y cuya controversia probablemente no era tan visible en épocas de bonanza económica. Es decir, los partidos políticos son más reacios al uso de este instrumento después de la crisis financiera de 2008, y debido también a la publicidad dada por algunos medios como la Fundación CIVIO, pues puede dañar su imagen de cara a las elecciones. Así, se constata como ha ido reduciéndose no solo el número de indultos en valor absoluto desde 2008, sino también su porcentaje indultado (ver Gráfico 2).

${ }^{16}$ No obstante, desconocemos estos aspectos porque la reforma de la Ley de 18 de junio de 1970 , de 1988, eliminó la obligación de motivar los indultos, tanto en su concesión como en su denegación.

17 Véase Jiménez y Abreu (2016) para más detalles. 
Otra cuestión a resaltar es que el porcentaje de indulto es mayor para aquellos solicitados por las Cofradías, respecto a los solicitados por el indultado. Pero sobre todo, es considerablemente menor si es el Equipo Técnico el que solicita el indulto (alrededor de 20 puntos porcentuales menos), lo que resalta el carácter subjetivo de estos descuentos de penas.

Finalmente, existe una relación positiva entre los días transcurridos entre la sentencia-concesión del indultos y el porcentaje de pena conmutado, por lo que los indultos podrían estar aplicándose en este sentido por motivos de equidad y justicia (ver nota al pie 3). Las concesiones de indultos excepcionales por el Año Jubilar tuvieron un efecto positivo sobre la pena indultada.

\section{Conclusiones}

El uso del indulto (o la conmuta) de las sanciones impuestas por el sistema judicial por parte de los gobiernos es una medida tan usual como polémica. Por un lado, la literatura académica ha mostrado los efectos negativos (Kwon et al., 2012) y la utilización sesgada de los mismos por parte de los Gobiernos que los conceden (Jiménez y Abreu, 2016). Por otro lado, los juristas consideran esta figura como una intromisión del poder político en el judicial (Pérez y Domínguez, 2002; Sánchez-Vera, 2008).

Partiendo de esta premisa, el presente trabajo ha tratado de ahondar en esta figura, pero no desde la perspectiva de su concesión sino de una segunda fase: la cuantía del indulto. Esta cuantía la valoramos como el porcentaje de la pena impuesta que es indultado o conmutado. Conocer los factores que puedan afectar a dicho porcentaje podría conceder una idea mayor de la tipología de los indultos e, incluso, determinar la proporcionalidad de los mismos.

La estimaciones por mínimos cuadrados ordinarios apuntan a una relación directa entre sanción impuesta y porcentaje de pena indultada. Ello supone que los indultos en España no son proporcionales ya que a mayor sanción impuesta, mayor porcentaje indultado (aunque este porcentaje no crece proporcionalmente para grandes penas). Esto puede ser debido a que los indultos de delitos de gravedad media/baja se conceden por motivos de buena conducta, edad, salud, etc., lo que hace que los tribunales sean más benevolentes. Además, que la multa y que el número de delitos cometido sea mayor, son aspectos determinantes para que el tribunal correspondiente decida reducir la pena indultada.

Ello, unido a otros resultados destacados relacionados con el Partido que lo concede -el Partido Popular aplica medidas de gracia más indulgentes que el PSOE-, la crisis económica, etc., son argumentos que se unen a la literatura ya existente y que apuntan a la utilización sesgada, carente de transparencia y basada en criterios diferentes de los de justicia o equidad social en los que deben estar basados.

Algunas medidas para mejorar el uso de esta herramienta pueden ir encaminadas a la abolición del indulto por delitos de corrupción, los cuales no hacen sino minar 
la confianza de la población en el sistema judicial (Santana, 2016), y la necesidad de volver a motivar los mismos, para que el proceso sea totalmente transparente.

\section{Referencias bibliográficas}

Austin, T. L., \& Hummer, D. (2000). The Effect of Legal and Extra-Legal Variables on the Recommending and Granting of a Pardon. Law and Policy, 22(1), 49-65.

Badules, D. (2016). Yo te perdono. Los indultos en el marco de la política penitenciaria en España: 1982-2014. España: Libros.com.

Barkow, R. E. (2009). The politics of forgiveness: reconceptualizing clemency. Federal Sentencing Reporter, 21(3), 153-159, ABA Roundtable on «Second Look» sentencing reforms.

Borja, E. (2011). Curso de Política Criminal. Valencia: Tirant lo Blanch.

Doval, A., Blanco, I., Fernández-Pacheco, C., Viana, C., \& Sandoval, J. C. (2011). Las concesiones de indultos en España (2000-2008). Revista Española de Investigación Criminológica (9), Artículo 5. Universidad de Alicante.

Eksterowicz, A., \& Roberts, R. N. (2006). The specter of presidential pardons. White house Studies Compendium (6), 319-331.

Fraile, M. (2005). Recensión del libro El indulto. Un análisis jurídico-constitucional, de Dña. R. García Mahamut (Ed). Revista Teoría y Realidad Constitucional, 16, $2^{\circ}$ semestre 2005, 507-511.

Harmon, T. R., Acker, J. R. \& Rivera, C. (2010). The power to be lenient: examining New York Governors'capital case clemency decisions. Justice Quarterly, 27(5), 742-764.

Heise, M. (2003). Mercy by the numbers: an empirical analysis of clemency and its structure. Virginia Law Review, 89(2), 239-310.

Herrero, I. (2012). El derecho de gracia: indultos (Tesis Doctoral). Universidad Nacional de Educación a Distancia, Madrid.

Jiménez, J. L., \& Abreu, J. (2016). Pardon does not forgive democracy: econometrical analysis of pardons in Spain. Hacienda Pública España / Review of Public Economics (216), 81-102.

Kwon, Y., Han, S. H., \& Nam, C. (2012). Estimating the costs of political populism: traffic violations pardons in Korea. Transportation Research Part A (46), 1449-1457.

Madrid, A. (2014). El indulto como excepción. Análisis de los indultos concedidos por el Gobierno español durante 2012. Revista Crítica Penal y Poder (6), 110-133. OSPDH, Universidad de Barcelona.

Morris, M. (1998). The overlooked relevance of the pardon power. En R. J. Barilleaux (Ed.), Presidential Frontiers: underexplored issues in White House politics, 79-98.

Pérez, J. L., \& Domínguez, F. (2002). El indulto como acto del Gobierno: una perspectiva constitucional (Especial análisis del «caso Liaño»). Revista de Derecho Político (53), 25-73.

Ruckman Jr., P.S. (1997). Executive Clemency in the United States: Origins, Development, and Analysis (1900-1993). Presidential Studies Quarterly (27), 251-271.

Ruckman Jr., P. S. (1998). President-centered and Presidency Centered Explanations of Federal Executive Clemency Policy. Presented at the Annual Meeting of the Southern Political Science Association: Atlanta, Georgia. 
Sánchez-Vera, J. (2008, abril). Una lectura crítica de la Ley del indulto, InDret: Revista para el análisis del Derecho, 2/2008, 1-32.

Santana, D.M. (2016). Desmontando el indulto (especial referencia a los delitos de corrupción), Revista Española de Derecho Constitucional (108), 51-91.

Whitford, A. B., \& Ochs, H. L. (2006). The Political Roots of Executive Clemency, American Politics Researchs, 34(6), 825-846.

Williston, S. (1915). Does a Pardon Blot out Guilt? Harvard Law Review, 28(7), 647-663. 
ANEXO

CUADRO A.I.

Representatividad de la muestra

\begin{tabular}{|l|c|c|c|}
\hline Año & Indultos totales & Indultos de la muestra & \% sobre el total \\
\hline 1995 & 47 & 24 & 51 \\
\hline 1996 & 530 & 191 & 36 \\
\hline 1997 & 738 & 248 & 34 \\
\hline 1998 & 1.582 & 441 & 28 \\
\hline 1999 & 741 & 265 & 36 \\
\hline 2000 & 1.744 & 526 & 30 \\
\hline 2001 & 245 & 125 & 51 \\
\hline 2002 & 253 & 157 & 62 \\
\hline 2003 & 299 & 196 & 66 \\
\hline 2004 & 320 & 178 & 56 \\
\hline 2005 & 457 & 257 & 56 \\
\hline 2006 & 517 & 358 & 69 \\
\hline 2007 & 543 & 380 & 70 \\
\hline 2008 & 442 & 337 & 76 \\
\hline 2009 & 438 & 288 & 66 \\
\hline 2010 & 404 & 226 & 56 \\
\hline 2011 & 359 & 224 & 62 \\
\hline 2012 & 534 & 328 & 61 \\
\hline 2013 & 12 & 5 & \\
\hline
\end{tabular}

FUENTE: Elaboración propia a través de la Fundación Ciudadana Civio.

NOTA: Para 1995 y 2013 solo están disponibles los meses de diciembre y enero, respectivamente. 